\title{
Research on Factors of Linear Algebra Learning Effect
}

\author{
Xin Wang ${ }^{1}$, Chong Hu${ }^{1}$, Yunhui Wang ${ }^{2}$ \\ ${ }^{1}$ School of Data Science and Software Engineering, Baoding University, Baoding, China \\ ${ }^{2}$ School of Automotive and Electronic Engineering, Baoding University, Baoding, China \\ Email: wangxincloud@163.com
}

How to cite this paper: Wang, X., Hu, C. and Wang, Y.H. (2020) Research on Factors of Linear Algebra Learning Effect. Journal of Applied Mathematics and Physics, 8, 1362-1373.

https://doi.org/10.4236/jamp.2020.87104

Received: July 6, 2020

Accepted: July 24, 2020

Published: July 27, 2020

Copyright $\odot 2020$ by author(s) and Scientific Research Publishing Inc. This work is licensed under the Creative Commons Attribution International License (CC BY 4.0).

http://creativecommons.org/licenses/by/4.0/ (c) (i) Open Access

\begin{abstract}
Linear algebra has a very important application in physics and technical disciplines. This article conducted a questionnaire survey on the factors that affect the effect of linear algebra learning; the questionnaire contains several aspects of learning attitude, learning interest, learning methods, teaching methods, etc.; based on recycling data, cross chi-square test and multiple logistic regression analysis are used to obtain the factors that affect the effect of linear algebra learning. The research results show that: learning methods, learning attitudes, teaching methods and elementary algebra basics are the main factors that affect the learning effect of linear algebra; among them, there are positive correlations between teaching methods, learning methods, learning attitudes and learning effects; teaching methods, learning methods 3. The three principal components of learning attitude are positively correlated. Based on the research and analysis, the following conclusions are drawn: finding a suitable learning method for the college students and maintaining a positive learning attitude are effective means to improve the linear algebra learning effect of the college students; in teaching, it is recommended to advance with the times, the teaching content and teaching methods innovate to stimulate students' interest in learning, thus improving the learning effect of college students' linear algebra courses.
\end{abstract}

\section{Keywords}

Linear Algebra, Learning Effect, Influencing Factors

\section{Introduction}

Linear algebra is an indispensable basic mathematics course for non-mathematics majors such as science and engineering majors and economic management ma- 
jors in colleges and universities. It plays an important role in cultivating students' mathematical quality and mathematical ability. However, the actual situation today is not optimistic, because the content of linear algebra courses is more and more complex and abstract; the content of the courses does not match the teaching hours; the traditional teaching mode still occupies the mainstream in today's teaching and other factors, resulting in low student initiative; in order to complete the teaching tasks, the teaching content set by themselves has to be limited to books; students rarely interpenetrate, associate, and apply linear algebra with other subjects. Therefore, it is very necessary to study the factors that affect the learning effect of linear algebra courses for college students. However, the current domestic papers on the effects of linear algebra study are all in the form of discussion, generally summarize the main factors affecting the learning effect, and then give suggestions. This article uses the actual collected data as the basis, through mathematical modeling to obtain the main influencing factors that affect students' linear algebra learning effect.

In [1], it is about stimulating students' interest in learning by improving teaching methods and increasing their enthusiasm for learning, so as to achieve good learning results.

In [2], starting from the current status of linear algebra learning, the influencing factors of the learning effect of the linear algebra course are discussed in terms of students' learning attitudes, learning methods, learning needs and teaching.

Reference [3], combined with its own teaching practice, discusses how to improve the quality of linear algebra teaching from the aspects of teaching methods and teaching methods.

In [4], according to the characteristics of the course "Linear Algebra", combined with its own teaching experience, suggestions are made from the aspects of cultivating students' interest in learning and improving teaching methods.

In [5], through the analysis of linear algebra course characteristics and academic conditions, the effects of linear algebra learning were studied in terms of enriching teaching methods, enhancing students' learning initiative, and stimulating students' interest in learning.

This article mainly analyzes the influencing factors of the linear algebra course, uses chi-square test to study and analyze the demographic variables and the initial algebra foundation; establish the correlation analysis and the establishment of the mathematical model of multiple logistic regression, and finally get the main impact of the linear algebra course learning effect Factors, hoping to provide guidance and suggestions for college students in linear algebra learning.

\section{Research Objects and Methods}

\subsection{Research Object}

The questionnaire survey target is college students in Baoding. Baoding is one of 
the central cities in the Beijing-Tianjin-Hebei region. There are 18 colleges and universities that provide a good environment for data collection. A total of 700 questionnaires were distributed and valid questionnaires were returned For 687 copies, the survey information is summarized in Table 1 , and Table 2.

\subsection{Research Tools}

The content of the questionnaire is divided into learning methods, learning attitudes, teaching methods, etc. The overall reliability coefficient of the scale question of this questionnaire reached 0.762 , which reached a good reliability level [see Table 3].

Through the tests, the approximate chi-square of the questionnaire is 3032.915 , and the validity reaches 0.888 [see Table 4].

Table 1. Demographic variables.

\begin{tabular}{ccccc}
\hline \multicolumn{5}{c}{ gender } \\
\hline & Frequency & Percentage & Effective Percentage & Cumulative Percentage \\
\hline Male & 210 & 30.6 & 30.6 & 30.6 \\
Female & 477 & 69.4 & 69.4 & 100 \\
Total & 687 & 100 & 100 & \\
\hline
\end{tabular}

Table 2. Demographic variables.

\begin{tabular}{ccccc}
\hline \multicolumn{5}{c}{ grade } \\
\hline & Frequency & Percentage & Effective Percentage & Cumulative Percentage \\
\hline First grade & 115 & 16.7 & 16.7 & 16.7 \\
Sophomore & 147 & 21.4 & 21.4 & 38.1 \\
Third grade & 139 & 20.2 & 20.2 & 58.4 \\
Fourth grade & 286 & 41.6 & 41.6 & 100 \\
Total & 687 & 100 & 100 & \\
\hline
\end{tabular}

Table 3. Reliability.

\begin{tabular}{cc}
\hline \multicolumn{2}{c}{ Reliability statistics } \\
\hline Cronbach's Alpha & Number of items \\
\hline 0.762 & 18 \\
\hline
\end{tabular}

Table 4. Validity.

\begin{tabular}{lcc}
\hline \multicolumn{3}{c}{ KMO and Bartlett's test } \\
\hline Sampling enough measurements Kaiser-Meyer-Olkin & 0.888 \\
& Approximate chi-square & 3032.915 \\
Bartlett's Sphericity test & df & 91 \\
& Sig. & 0.000 \\
\hline
\end{tabular}




\subsection{Statistical Analysis and Data Processing}

The software is used to process the data, and the difference between demographic variables and elementary algebra is cross-chi-squared; the factors that affect the effect of linear algebra learning and the correlation between the factors are analyzed by correlation analysis and multiple regression analysis.

\section{Research Results and Analysis}

Two types of data are involved in the questionnaire, which are quantitative and categorical data. Quantitative data are generally continuous data in mathematics, and the more common in questionnaires are scales; categorical data is generally mathematics. Discrete data, such as gender and age, are more common in the questionnaire. This questionnaire has both categorized and quantitative data, so it uses cross-chi-square, correlation analysis, and multiple regression methods.

\subsection{Cross Chi-Square Test}

\subsubsection{Gender}

It can be seen from the cross-table analysis that the Pearson chi-square value of gender on linear algebra is greater than 0.05 , indicating that gender has no significant effect on the learning effect of linear algebra; while the value and the value are less than 0.1 , the relationship is not close, that is, the effect of gender on the linear algebra learning No obvious relationship [see Table 5 and Table $6]$.

\subsubsection{Grade}

A questionnaire survey was conducted on students of different grades in various colleges.

Table 5. Gender and linear algebra.

\begin{tabular}{cccc}
\hline \multicolumn{3}{c}{ Chi-square test } & \\
\hline Pearson chi-square & Value & df & Progressive Sig. (two-sided) \\
Likelihood ratio & $1.204 \mathrm{a}$ & 3 & 0.752 \\
Linear and linear combination & 1.148 & 3 & 0.765 \\
N in valid cases & 0.043 & 1 & 0.835 \\
\hline
\end{tabular}

a. The expected count of 0 cells $(0 \%)$ is less than 5 . The minimum expected count is 6.72 .

Table 6. Corresponding phi value and v value.

\begin{tabular}{cccc}
\hline \multicolumn{3}{c}{ Symmetry } \\
\\
\hline \multirow{2}{*}{ Calibration by scalar } & $\varphi$ & Value & Approximate Sig. \\
\hline N in valid cases & Cramer's $V$ & 0.042 & 0.752 \\
& & 0.042 & 0.752 \\
\hline
\end{tabular}


It can be seen from the cross-table analysis that the Pearson chi-square value of grade for linear algebra is less than 0.05 , indicating that grade has a significant effect on the learning effect of linear algebra. At the same time, the value and the value are greater than 0.1 , indicating that the relationship is close, that is, the grade has a linear algebra learning effect. There is an obvious relationship.

\subsubsection{Results with Elementary Algebra}

From the cross-table analysis, it can be seen that the Pearson chi-square value of elementary algebra on linear algebra is less than 0.05 , indicating that elementary algebra has a significant effect on the learning effect of linear algebra; while the value and the value are greater than 0.1 , it means that the relationship between elementary algebra and linear algebra is close, that is, elementary algebra is linear. There is a clear relationship between learning effectiveness.

\subsection{Related Analysis [6]}

Before conducting relevant analysis, it is necessary to reduce the dimensionality of all questions in the questionnaire, that is, the closest content in the questionnaire question is classified into one category, and the non-close content is divided into different categories, the distance within the group is the shortest, and the distance between the groups is the farthest.

\subsubsection{Dimensionality Reduction}

Use principal component factor analysis to achieve dimensionality reduction, dimensionality reduction steps [see Table 7(a) and Table 7(b)]:

1) Form the original data into a matrix by row, and name this matrix $A$;

2) Subtract the average value of each row of matrix $A$ from each row, and the sample mean formula is:

$$
\bar{x}=\frac{x_{1}+x_{2}+\cdots+x_{m}}{m}
$$

3) Find the correlation coefficient matrix $C$ corresponding to the variable

$$
C=\frac{1}{m} A^{\mathrm{T}} A
$$

4) Find the eigenvalue and eigenvector corresponding to the correlation coefficient matrix $C$; the eigenvalue and eigenvector of the data matrix

$$
|\lambda E-C|=0
$$

Each characteristic value is obtained from the SPSS analysis results:

$$
\begin{aligned}
& \lambda_{1}=4.888, \quad \lambda_{2}=1.178, \quad \lambda_{3}=1.162, \quad \lambda_{4}=0.868, \quad \lambda_{5}=0.710, \\
& \lambda_{6}=0.694, \quad \lambda_{7}=0.670, \quad \lambda_{8}=0.566, \quad \lambda_{9}=0.525, \quad \lambda_{10}=0.490, \\
& \lambda_{11}=0.468, \quad \lambda_{12}=0.433, \quad \lambda_{13}=0.412, \quad \lambda_{14}=0.328
\end{aligned}
$$

Sort the calculated feature values in descending order, and then calculate the corresponding feature vector, that is

$$
(\lambda E-C) x_{i}=0(i=1,2, \cdots, 14)
$$


Table 7. Correlation matrix.

(a)

\begin{tabular}{|c|c|c|c|c|c|c|c|c|}
\hline \multicolumn{9}{|c|}{ Correlation matrix } \\
\hline & & Q5 & Q6 & Q7 & Q8 & Q9 & Q10 & Q11 \\
\hline \multirow{14}{*}{ Related } & Q5 & 1 & 0.54 & 0.391 & 0.348 & 0.504 & 0.138 & 0.31 \\
\hline & Q6 & 0.54 & 1 & 0.462 & 0.329 & 0.55 & 0.14 & 0.28 \\
\hline & Q7 & 0.391 & 0.462 & 1 & 0.37 & 0.442 & 0.193 & 0.258 \\
\hline & Q8 & 0.348 & 0.329 & 0.37 & 1 & 0.349 & 0.259 & 0.368 \\
\hline & Q9 & 0.504 & 0.55 & 0.442 & 0.349 & 1 & 0.195 & 0.313 \\
\hline & Q10 & 0.138 & 0.14 & 0.193 & 0.259 & 0.195 & 1 & 0.25 \\
\hline & Q11 & 0.31 & 0.28 & 0.258 & 0.368 & 0.313 & 0.25 & 1 \\
\hline & Q12 & 0.204 & 0.219 & 0.187 & 0.232 & 0.224 & 0.16 & 0.331 \\
\hline & Q13 & 0.344 & 0.352 & 0.339 & 0.446 & 0.375 & 0.314 & 0.408 \\
\hline & Q14 & 0.315 & 0.329 & 0.298 & 0.361 & 0.338 & 0.252 & 0.291 \\
\hline & Q16 & 0.234 & 0.182 & 0.229 & 0.208 & 0.228 & 0.16 & 0.253 \\
\hline & Q17 & 0.193 & 0.181 & 0.172 & 0.206 & 0.208 & 0.18 & 0.256 \\
\hline & Q18 & 0.262 & 0.261 & 0.189 & 0.172 & 0.246 & 0.092 & 0.307 \\
\hline & Q19 & 0.283 & 0.227 & 0.198 & 0.174 & 0.241 & 0.113 & 0.316 \\
\hline
\end{tabular}

(b)

\begin{tabular}{|c|c|c|c|c|c|c|c|c|}
\hline \multicolumn{9}{|c|}{ Correlation matrix } \\
\hline & & Q12 & Q13 & Q14 & Q16 & Q17 & Q18 & Q19 \\
\hline \multirow{14}{*}{ Related } & Q5 & 0.204 & 0.344 & 0.315 & 0.234 & 0.193 & 0.262 & 0.283 \\
\hline & Q6 & 0.219 & 0.352 & 0.329 & 0.182 & 0.181 & 0.261 & 0.227 \\
\hline & Q7 & 0.187 & 0.339 & 0.298 & 0.229 & 0.172 & 0.189 & 0.198 \\
\hline & Q8 & 0.232 & 0.446 & 0.361 & 0.208 & 0.206 & 0.172 & 0.174 \\
\hline & Q9 & 0.224 & 0.375 & 0.338 & 0.228 & 0.208 & 0.246 & 0.241 \\
\hline & Q10 & 0.16 & 0.314 & 0.252 & 0.16 & 0.18 & 0.092 & 0.113 \\
\hline & Q11 & 0.331 & 0.408 & 0.291 & 0.253 & 0.256 & 0.307 & 0.316 \\
\hline & Q12 & 1 & 0.464 & 0.232 & 0.27 & 0.246 & 0.278 & 0.286 \\
\hline & Q13 & 0.464 & 1 & 0.426 & 0.287 & 0.276 & 0.318 & 0.34 \\
\hline & Q14 & 0.232 & 0.426 & 1 & 0.192 & 0.233 & 0.201 & 0.208 \\
\hline & Q16 & 0.27 & 0.287 & 0.192 & 1 & 0.53 & 0.538 & 0.497 \\
\hline & Q17 & 0.246 & 0.276 & 0.233 & 0.53 & 1 & 0.517 & 0.541 \\
\hline & Q18 & 0.278 & 0.318 & 0.201 & 0.538 & 0.517 & 1 & 0.651 \\
\hline & Q19 & 0.286 & 0.34 & 0.208 & 0.497 & 0.541 & 0.651 & 1 \\
\hline
\end{tabular}

5) Sort the obtained eigenvectors from largest to smallest eigenvalues, and take the first $K$ to form the matrix $P$; the values of the matrix $P$ are shown in Table 8 . 
Table 8. Correlation matrix.

\begin{tabular}{|c|c|c|c|}
\hline & \multicolumn{3}{|c|}{ Ingredients } \\
\hline & 1 & 2 & 3 \\
\hline Effective preview & 0.128 & 0.166 & -0.314 \\
\hline Regularly review what you have learned & 0.128 & 0.209 & -0.335 \\
\hline The habit of wrong questions or key records & 0.118 & 0.194 & -0.183 \\
\hline High concentration of lectures & 0.119 & 0.173 & 0.192 \\
\hline There are plans for free time after class & 0.132 & 0.195 & -0.251 \\
\hline Take each test seriously & 0.078 & 0.081 & 0.469 \\
\hline Actively interact with teachers & 0.123 & 0.023 & 0.228 \\
\hline Recognize the importance of the course & 0.106 & -0.049 & 0.296 \\
\hline Positive learning attitude & 0.143 & 0.066 & 0.292 \\
\hline The quality of job completion is better & 0.115 & 0.132 & 0.177 \\
\hline The teacher teaches classic math cases to stimulate curiosity & 0.119 & -0.281 & -0.061 \\
\hline Teachers have various teaching methods & 0.117 & -0.297 & -0.012 \\
\hline $\begin{array}{l}\text { Teachers in the class will create } \\
\text { problem situations and heuristic teaching }\end{array}$ & 0.127 & -0.306 & -0.152 \\
\hline The teacher's teaching method is rich & 0.128 & -0.302 & -0.117 \\
\hline
\end{tabular}

6) After passing the formula. $B=C P, B$ is the result after dimensionality reduction

$$
b_{j}=\sum_{i=1}^{14} c_{i} p_{i} ;(i=1,2,3, \cdots, 14)(j=1,2,3)
$$

where $p_{i}$ represents the feature vector, and $c_{i}$ represents the variable sequence of the $i$ th question. Substitute the corresponding values into:

$$
\begin{aligned}
b_{1}= & 0.128 c_{1}+0.128 c_{2}+0.118 c_{3}+0.119 c_{4}+0.132 c_{5}+0.078 c_{6}+0.123 c_{7} \\
& +0.106 c_{8}+0.143 c_{9}+0.115 c_{10}+0.119 c_{11}+0.117 c_{12}+0.127 c_{13}+0.128 c_{14} \\
b_{2}= & 0.166 c_{1}+0.296 c_{2}+0.194 c_{3}+0.173 c_{4}+0.195 c_{5}+0.081 c_{6}+0.023 c_{7} \\
& -0.049 c_{8}+0.066 c_{9}+0.132 c_{10}-0.281 c_{11}-0.297 c_{12}-0.306 c_{13}-0.302 c_{14} \\
b_{3}= & -0.314 c_{1}-0.335 c_{2}-0.183 c_{3}+0.192 c_{4}-0.251 c_{5}+0.469 c_{6}+0.228 c_{7} \\
& +0.296 c_{8}+0.292 c_{9}+0.117 c_{10}-0.061 c_{11}-0.012 c_{12}-0.152 c_{13}-0.117 c_{14}
\end{aligned}
$$

so as to get the final dimensionality reduction result.

Before using factor analysis for dimensionality reduction, you need to check the suitability of the sample's factor analysis through the $K M O$ and Bartlett spherical tests; the $K M O$ value of this article is 0.859 . It reached a good level of fit [see Table 9].

\subsubsection{Model Principle}

Correlation analysis is a statistical method to study whether there is a correlation between random variables. Calculation of correlation coefficient: 
Table 9. Explained total variance.

\begin{tabular}{|c|c|c|c|c|c|c|c|c|c|}
\hline & \multicolumn{4}{|c|}{ Ingredients } & \multicolumn{3}{|c|}{$\begin{array}{l}\text { Extract square } \\
\text { sum load }\end{array}$} & \multicolumn{2}{|c|}{$\begin{array}{c}\text { Rotate square } \\
\text { sum loading }\end{array}$} \\
\hline & Total & $\begin{array}{c}\% \text { Of } \\
\text { variance }\end{array}$ & $\begin{array}{c}\text { Cumulative } \\
\%\end{array}$ & Total & $\begin{array}{c}\% \text { Of } \\
\text { variance }\end{array}$ & $\begin{array}{c}\text { Cumulative } \\
\%\end{array}$ & Total & $\begin{array}{c}\% \text { Of } \\
\text { variance }\end{array}$ & $\begin{array}{c}\text { Cumulative } \\
\%\end{array}$ \\
\hline 1 & 4.097 & 37.245 & 37.245 & 4.097 & 37.245 & 37.245 & 2.692 & 24.469 & 24.469 \\
\hline 2 & 1.744 & 15.856 & 53.101 & 1.744 & 15.856 & 53.101 & 2.675 & 24.322 & 48.792 \\
\hline 3 & 1.055 & 9.589 & 62.69 & 1.055 & 9.589 & 62.69 & 1.529 & 13.898 & 62.69 \\
\hline 4 & 0.702 & 6.378 & 69.069 & & & & & & \\
\hline 5 & 0.644 & 5.851 & 74.92 & & & & & & \\
\hline 6 & 0.565 & 5.137 & 80.057 & & & & & & \\
\hline 7 & 0.498 & 4.525 & 84.582 & & & & & & \\
\hline 8 & 0.487 & 4.426 & 89.009 & & & & & & \\
\hline 9 & 0.449 & 4.078 & 93.086 & & & & & & \\
\hline 10 & 0.433 & 3.932 & 97.019 & & & & & & \\
\hline 11 & 0.328 & 2.981 & 100 & & & & & & \\
\hline
\end{tabular}

$$
r=\frac{l_{x y}}{\sqrt{l_{x x} l_{y y}}}=\frac{\sum_{i=1}^{n} \frac{(X-\bar{X})(Y-\bar{Y})}{n-1}}{\sqrt{\sum_{i=1}^{n} \frac{(X-\bar{X})^{2}}{n-1}} \sqrt{\sum_{i=1}^{n} \frac{(Y-\bar{Y})^{2}}{n-1}}}
$$

where $l_{i j}$ represents the covariance of variables $i$ and $j ; \bar{X}$ represents the mean of the variables.

Judging from the scatterplot that there is a linear relationship between the three principal components, the Pearson correlation analysis is used to obtain [see Table 10].

\subsubsection{Results and Analysis}

$$
r_{12}=\frac{l_{12}}{\sqrt{l_{11} l_{22}}}=\frac{0.1}{\sqrt{0.782 \times 0.150}}=0.291
$$

Empathy

$$
r_{13}=0.080 ; r_{14}=0.334
$$

The subscript of $r$ is 1 line generation learning effect, 2 learning method, 3 teaching method, 4 learning attitude.

It can be seen from the above table that the correlation coefficient between linear algebra scores and learning methods is 0.291 , and the value is less than 0.05 . Therefore, the positive correlation between the two variables is statistically significant, and the linear algebra learning effect increases with the suitability of the learning method. In the same way, the correlation coefficients of linear algebra and learning attitude and teaching methods are 0.334 and 0.080 , and the values are both less than 0.05 , and the positive correlation between the two variables is 
Table 10. Correlation.

\begin{tabular}{|c|c|c|c|c|c|}
\hline \multicolumn{6}{|c|}{ Correlation } \\
\hline & & $\begin{array}{l}\text { Teaching } \\
\text { Method }\end{array}$ & $\begin{array}{l}\text { Learning } \\
\text { Method }\end{array}$ & $\begin{array}{l}\text { Learning } \\
\text { Attitude }\end{array}$ & $\begin{array}{c}\text { Linear } \\
\text { Algebra Results }\end{array}$ \\
\hline \multirow[t]{5}{*}{$\begin{array}{l}\text { Teaching } \\
\text { Method }\end{array}$} & Pearson Correlation & 1 & $0.348^{\star *}$ & $0.338^{\star *}$ & $0.080^{*}$ \\
\hline & Significance (both sides) & & 0 & 0 & 0.037 \\
\hline & $\begin{array}{l}\text { Sum of square } \\
\text { and cross product }\end{array}$ & 126.226 & 39.619 & 27.414 & 20.707 \\
\hline & Covariance & 0.184 & 0.058 & 0.04 & 0.03 \\
\hline & $\mathrm{N}$ & 687 & 687 & 687 & 687 \\
\hline \multirow[t]{5}{*}{$\begin{array}{l}\text { Learning } \\
\text { Method }\end{array}$} & Pearson Correlation & $0.348^{\star \star}$ & 1 & $0.483^{* *}$ & $0.291^{* *}$ \\
\hline & Significance (both sides) & 0 & & 0 & 0 \\
\hline & $\begin{array}{l}\text { Sum of square } \\
\text { and cross product }\end{array}$ & 39.619 & 102.693 & 35.322 & 68.288 \\
\hline & Covariance & 0.058 & 0.15 & 0.051 & 0.1 \\
\hline & $\mathrm{N}$ & 687 & 687 & 687 & 687 \\
\hline \multirow[t]{5}{*}{$\begin{array}{l}\text { Learning } \\
\text { Attitude }\end{array}$} & Pearson Correlation & $0.338^{\star *}$ & $0.483^{* *}$ & 1 & $0.334^{* *}$ \\
\hline & Significance (both sides) & 0 & 0 & & 0 \\
\hline & $\begin{array}{l}\text { Sum of square } \\
\text { and cross product }\end{array}$ & 27.414 & 35.322 & 52.07 & 55.876 \\
\hline & Covariance & 0.04 & 0.051 & 0.076 & 0.081 \\
\hline & $\mathrm{N}$ & 687 & 687 & 687 & 687 \\
\hline \multirow[t]{5}{*}{$\begin{array}{c}\text { Linear } \\
\text { Algebra Results }\end{array}$} & Pearson Correlation & $0.080^{*}$ & $0.291^{\star *}$ & $0.334^{\star *}$ & 1 \\
\hline & Significance (both sides) & 0.037 & 0 & 0 & \\
\hline & $\begin{array}{l}\text { Sum of square } \\
\text { and cross product }\end{array}$ & 20.707 & 68.288 & 55.876 & 536.509 \\
\hline & Covariance & 0.03 & 0.1 & 0.081 & 0.782 \\
\hline & $\mathrm{N}$ & 687 & 687 & 687 & 687 \\
\hline
\end{tabular}

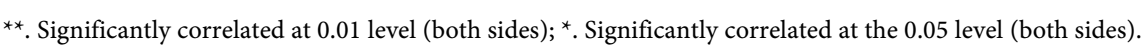

also statistically significant, that is, the more positive the learning attitude, the more effective the linear algebra learning effect Good; the more the teaching method is recognized by the students, the better the effect of online learning [see Table 11].

$$
\begin{aligned}
& r_{12}^{\prime}=\frac{l_{12}}{\sqrt{l_{11} l_{22}}}=\frac{0.058}{\sqrt{0.150 \times 0.184}}=0.348 \\
& r_{13}^{\prime}=\frac{l_{13}}{\sqrt{l_{11} l_{33}}}=\frac{0.051}{\sqrt{0.150 \times 0.076}}=0.483
\end{aligned}
$$


Table 11. Correlation between the three principal components.

\begin{tabular}{|c|c|c|c|c|}
\hline \multicolumn{5}{|c|}{ Correlation between the three principal components } \\
\hline & & $\begin{array}{l}\text { Teaching } \\
\text { Method }\end{array}$ & $\begin{array}{l}\text { Learning } \\
\text { Attitude }\end{array}$ & $\begin{array}{l}\text { Learning } \\
\text { Method }\end{array}$ \\
\hline \multirow[t]{5}{*}{ Teaching Method } & Pearson Correlation & 1 & $0.338^{\star *}$ & $0.348^{\star *}$ \\
\hline & Significance (both sides) & & 0 & 0 \\
\hline & Sum of square and cross product & 126.226 & 27.414 & 39.619 \\
\hline & Covariance & 0.184 & 0.04 & 0.058 \\
\hline & $\mathrm{N}$ & 687 & 687 & 687 \\
\hline \multirow[t]{5}{*}{ Learning Attitude } & Pearson Correlation & $0.338^{\star *}$ & 1 & $0.483^{\star *}$ \\
\hline & Significance (both sides) & 0 & & 0 \\
\hline & Sum of square and cross product & 27.414 & 52.07 & 35.322 \\
\hline & Covariance & 0.04 & 0.076 & 0.051 \\
\hline & $\mathrm{N}$ & 687 & 687 & 687 \\
\hline \multirow[t]{5}{*}{ Learning Method } & Pearson Correlation & $0.348^{\star *}$ & $0.483^{* *}$ & 1 \\
\hline & Significance (both sides) & 0 & 0 & \\
\hline & Sum of square and cross product & 39.619 & 35.322 & 102.693 \\
\hline & Covariance & 0.058 & 0.051 & 0.15 \\
\hline & $\mathrm{N}$ & 687 & 687 & 687 \\
\hline
\end{tabular}

**. Significantly correlated at 0.01 level (both sides).

$$
r_{23}^{\prime}=\frac{l_{23}}{\sqrt{l_{22} l_{33}}}=\frac{0.040}{\sqrt{0.184 \times 0.076}}=0.338
$$

The 1 in the lower subscript of $r$ is the learning method, 2 is the teaching method, and 3 is the learning attitude; the upper subscript of $r$ is the correlation coefficient for distinguishing the line generation and the three principal components.

We can see from the correlation table between the three principal components that there is a significant positive correlation between the three major components.

\subsection{Multiple Logistic Regression [7]}

\subsubsection{Model Introduction}

Multiple logistic regression studies whether the variable $X$ will affect $Y$.

The multiple logistic regression equation is:

$$
\begin{aligned}
& \operatorname{logit}\left(P_{b}\right)=\ln \left(\frac{P(Y=b)}{P(Y=a)}\right)=\beta_{0}+\beta_{11} X_{1}+\beta_{12} X_{2}+\cdots+\beta_{1 p} X_{p} \\
& \operatorname{logit}\left(P_{c}\right)=\ln \left(\frac{P(Y=c)}{P(Y=a)}\right)=\beta_{0}+\beta_{11} X_{1}+\beta_{12} X_{2}+\cdots+\beta_{1 p} X_{p}
\end{aligned}
$$

where $Y=a$ is the control group of $b$ and $c$. 


\subsubsection{Results and Analysis}

Likelihood ratio test results show whether the model has statistical significance; the independent variable learning method, the addition of learning attitude is statistically significant $(p<0.001)$, the independent variable teaching method has no significant effect on the dependent variable.

$$
\begin{aligned}
\operatorname{logit}\left(P_{b}\right) & =\ln \left(\frac{P(Y=b)}{P(Y=a)}\right) \\
& =\beta_{0}+\beta_{11} x_{1}+\beta_{12} x_{2}+\beta_{13} x_{3} \\
& =3.078+0.483 x_{1}-0.394 x_{2}-1.956 x_{3}
\end{aligned}
$$

Empathy

$$
\begin{aligned}
& \operatorname{logit}\left(P_{c}\right)=5.544+0.55 x_{1}-1.259 x_{2}-2.752 x_{3} \\
& \operatorname{logit}\left(P_{d}\right)=5.023+0.41 x_{1}-1.823 x_{2}-3.246 x_{3}
\end{aligned}
$$

The above formula a indicates the reference category, that is, the line generation score is more than 85 points, $b$ is the linear algebra score from 75 to 85 points, $c$ is the linear algebra score from 60 to 75 points, and $d$ represents the linear algebra score is 60 points below; $i j$ represents the corresponding $B$ value in the parameter estimation table; $P_{b}$ represents the probability of event $b$ compared to event $a$.

\section{Conclusions}

1) Learning attitudes, learning methods, elementary algebra and grade all have a significant impact on the effects of linear algebra learning; teaching methods have a slightly lower impact on the effects of linear algebra learning; gender will not have a significant impact on the effects of linear algebra learning.

2) Your own learning method and good learning attitude are effective means to achieve good learning effect.

3) Teachers can make appropriate innovations in teaching content and teaching methods, and improve the teaching level by increasing students' interest in learning.

This article mainly analyzes the influencing factors of the linear algebra course, uses chi-square test to study and analyze the demographic variables and the initial algebra foundation; establishes the correlation analysis and the mathematical model of multiple logistic regression; and finally gets the main impact of the linear algebra course learning effect factors, hoping to provide guidance and suggestions for college students in linear algebra learning.

This article has studied the effects of linear algebra learning on college students, but the specific effects of grades, elementary algebra, etc. on the effects of linear algebra learning can be further studied.

\section{Funding}

Supported by Hebei Higher Education Teaching Research and Practice Project (2017GJJG261); Hebei Province Education Department Hebei University Sci- 
ence and Technology Research Youth Fund Project (QN2017502); Hebei Higher Education Teaching Research and Practice Project (2019GJJG483).

\section{Conflicts of Interest}

The authors declare no conflicts of interest regarding the publication of this paper.

\section{References}

[1] Wang, Y. and Sun, F. (2017) Thinking about the Teaching Method of Linear Algebra Course. Journal of Tianjin Vocational and Technical Normal University, 27, $62-64+74$.

[2] Cui, N. and Zhu, D. (2020) Research on Teaching Reform Measures of Linear Algebra Course. Mathematics Learning and Research, No. 3, 122.

[3] Yu, L., Dong, Y. and Yang, H. (2012) Thinking on the Teaching System and Teaching Method of Linear Algebra Course. Science and Technology Information, No. $416,36+39$.

[4] Lei, E. (2002) Discussion on the Teaching of "Linear Algebra". Journal of Taiyuan University of Technology (Social Science Edition), No. 31, 84-85.

[5] Gao, F. (2019) The Practice and Exploration of the Teaching Reform of the Course "Linear Algebra" under the Background of New Engineering. Contemporary Educational Practice and Teaching Research, No. 23, 205-206.

[6] Fan, J. and Mei, C. (2002) Data Analysis. Science Press, Beijing, 142-146.

[7] Jiang, Q., Xie, J., et al. (2015) Mathematical Model. Higher Education Press, Beijing, 352-355. 